\title{
Análise de crescimento do feijoeiro submetido a quatro níveis de umidade do solo
}

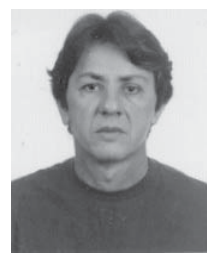

José Q. Nóbrega ${ }^{1}$, Tantravahi V. R. Rao ${ }^{2}$, Napoleão E. de M. Beltrão ${ }^{3} \&$ José Fideles Filho ${ }^{1}$

\footnotetext{
${ }^{1}$ EMEPA-PB, Estrada da Imbaúba, km 3, Lagoa Seca, PB. Fone: (83) 322-1872. E-mail: nobregajq@uol.com.br (Foto) 2 DCA/CCT/UFPB, R. Aprígio Veloso, 882, Bodocongó, CEP 58109-970, Campina Grande, PB. Fone: (83) $310-1031$. E-mail: ramana@dca.ufpb.br

${ }^{3}$ EMBRAPA, R. Osvaldo Cruz, 1143, Centenário, CEP 58107-720, Campina Grande, PB. Fone: (83) $341-3608$.

E-mail: nbeltrão@cnpa.embrapa.br
}

Protocolo $109-12 / 7 / 2001$

\begin{abstract}
Resumo: A presente pesquisa foi desenvolvida na Estação Experimental de Lagoa Seca, da Empresa Estadual de Pesquisa Agropecuária da Paraíba, EMEPA-PB, tendo como objetivo identificar as conseqüências do conteúdo de umidade do solo, em algumas variáveis de crescimento, da cultura do feijão (Phaseolus vulgaris L.). O delineamento estatístico utilizado foi o de blocos casualizados, com quatro tratamentos e quatro repetições. Os tratamentos basearam-se em diferentes lâminas de irrigação: 80, 160, 320 e 140,2 mm, distribuídas nas fases fenológicas da cultura e fundamentadas em estudos anteriormente desenvolvidos, e na umidade do solo. Os efeitos dos diferentes regimes de irrigação foram avaliados mediante as variáveis de crescimento, fitomassa total, área foliar, índice de área foliar, taxa de assimilação líquida e razão da área foliar, as quais apresentaram valores diferenciados em resposta aos tratamentos empregados, com aumento de valores nas plantas com maior suprimento de água.
\end{abstract}

Palavras-chave: Phaseolus vulgaris, lâmina de irrigação, variáveis de crescimento

\section{Growth analysis of a bean crop submitted to four levels of soil humidity}

\begin{abstract}
The research work was conducted at the Experimental Station of Lagoa Seca, located at the Empresa Estadual de Pequisa Agropecuária da Paraíba, EMEPA-PB, with the objective of identifying the consequences of soil moisture content upon the growth variables of the bean (Phaseolus vulgaris L.) crop. The statistical design used was the randomized blocks, with four treatments and four replications. The treatments were based on different irrigation levels: 80 , 160,320 and $140.2 \mathrm{~mm}$, distributed in the different phenological phases of the crop and based on the results of the previous studies and in the soil humidity. The effects of the different irrigation regimes were evaluated by means of the growth variables, while total phytomass, leaf area, leaf area index, net assimilation rate and leaf area ratio which showed differentiated values in which response to the water treatments employed, with increased values in plants with higher supplies of water.
\end{abstract}

Key words: Phaseolus vugaris, irrigation levels, growth variables

\section{INTRODUÇÃO}

O feijoeiro é classificado como planta sensível, tanto à deficiência hídrica quanto ao excesso de água no solo. O requerimento de água pela cultura é variável com o seu estádio de desenvolvimento. O consumo de água aumenta de um valor mínimo na germinação até um valor máximo na floração e na formação de vagens, decrescendo a partir do início da maturação. Guimarães et al. (1982) encontraram 2,3, 7,1 e $1,5 \mathrm{~mm} \mathrm{~d}^{-1}$ de consumo, aos 10 dias após a germinação, durante a floração e início da maturação, respectivamente.
Os efeitos do nível de umidade do solo no feijoeiro manifestam-se ao longo do seu ciclo e nas diferentes partes da planta. Em geral, o que mais interessa são os efeitos do déficit hídrico sobre o crescimento e o desenvolvimento da cultura, o que, conseqüentemente, limita o rendimento (Mañas \& Valero, 1993).

O crescimento de um vegetal depende, em termos gerais, da divisão, do desenvolvimento e da expansão celular, processos esses sensíveis ao estresse hídrico, principalmente na fase de alongamento celular. Depois desta fase, a célula se encontra preparada para expandir, bastando que haja pressão hidrostática interna, ou de turgor. 
A água, além de ser o principal constituinte do protoplasma, participa diretamente de inúmeras reações químicas, responsáveis pela turgescência celular. A redução da absorção de água e a conseqüente desidratação das células, comprometem os processos fisiológicos afetando, assim, todos os componentes de crescimento (Páez et al., 1995). A perda acentuada de água reduz a multiplicação e o alongamento das células, resultando em plantas menores e, em conseqüência, na redução da área foliar. A limitação na área foliar pode ser considerada uma primeira reação das plantas ao déficit hídrico, (Taiz \& Zeiger, 1991). Para Fernández et al. (1996) a área foliar é um importante fator da produção e determina o uso da água pela planta e seu potencial de produtividade é severamente inibido quando exposta ao déficit hídrico.

Conforme Bascur et al. (1985a) durante o desenvolvimento do feijoeiro a atividade fotossintética aumenta com o crescimento da área foliar, até a sua expansão máxima. Entretanto, segundo Fancelli \& Dourado Neto (1991) e Guimarães (1996) a deficiência hídrica poderá paralisar o crescimento foliar, tendo efeito indireto no rendimento de grãos, pela redução da área foliar fotossinteticamente ativa.

Bascur et al. (1985b) estudando o efeito da umidade do solo sobre cultivares de feijão, verificaram que plantas submetidas a estresse hídrico sofreram forte redução da área foliar e no rendimento, mas apresentaram maior acúmulo de matéria seca em talos e ramos. Observaram, também, que variedades de feijoeiro com resistência à seca apresentam maior manutenção foliar, que resulta em maior peso de matéria seca e produtividade. Resultados semelhantes foram obtidos por Resende et al. (1981) e Stone et al. (1988). Em função da deficiência de informações com as cultivares locais, desenvolvidas no Nordeste e se considerando, ainda, que as possibilidades do estresse hídrico são plenas nesta região sendo análise de crescimento uma boa ferramenta para o entendimento da produção, realizou-se o presente trabalho.

\section{MATERIAL E MÉTODOS}

Este trabalho foi desenvolvido na Estação Experimental de Lagoa Seca, da Empresa Estadual de Pesquisa Agropecuária da Paraíba, EMEPA-PB. Lagoa Seca está localizada na microrregião homogênea do agreste paraibano, com coordenadas geográficas de $7^{\circ} 09^{\prime} \mathrm{S}$ e $35^{\circ} 52^{\prime} \mathrm{W}$ e altitude de $634 \mathrm{~m}$. O clima é o tropical chuvoso, com estações secas no verão. A pluviosidade média dos últimos 14 anos é de $940 \mathrm{~mm}$, com maior incidência de chuva no período entre março e agosto. A umidade relativa do ar média é de aproximadamente $60 \%$ e a temperatura média anual é de $25^{\circ} \mathrm{C}$. O solo é do tipo Neossolo Regolítico com textura arenosa, segundo laboratório da EMBRAPA-CNPA, Campina Grande PB.

Os períodos estudados foram de maio a julho de 1999 e de janeiro a março de 2000. Nos experimentos, cada parcela ocupou uma área total de $15 \mathrm{~m}^{2}(3 \times 5 \mathrm{~m})$, constituída por seis fileiras de $5 \mathrm{~m}$ de comprimento, espaçadas de $0,50 \mathrm{~m}$ entre linhas e $0,25 \mathrm{~m}$ entre plantas. $\mathrm{O}$ delineamento experimental para o primeiro experimento consistiu de blocos ao acaso, com quatro tratamentos e cinco repetições. As densidades de semeadura de $80.000,160.000,240.000$ e 320.000 plantas por hectare, representaram os tratamentos, enquanto no segundo experimento os tratamentos constaram de quatro lâminas de água, foram utilizadas quatro repetições e a população 240.000 plantas ha $^{-1}$ para todos os tratamentos. Os tratamentos desse experimento basearam-se na umidade do solo e em dados de precipitação ocorrida no primeiro experimento, que teve como objetivo definir a densidade populacional, que proporcionou maior rendimento, e as lâminas de irrigação a serem aplicadas. Durante o ciclo da cultura obtiveram-se dados de precipitação, que foram relacionados com as diferentes fases fenológicas do feijoeiro. O total de água precipitada foi de $182,5 \mathrm{~mm}$, assim distribuídos: $64 \mathrm{~mm}$ foram verificados na fase I - germinação ao início da floração, com duração de $32 \mathrm{~d} ; 37,5 \mathrm{~mm}$ na fase II - floração, com duração de $15 \mathrm{~d}$ e $81 \mathrm{~mm}$ na fase III desenvolvimento de vagens à maturidade, com duração de 27 d. Partindo desses dados de precipitação, o total de água de cada fase foi transformado em consumo diário e aplicado no segundo experimento, em turno de rega de $3 \mathrm{~d}$ nos tratamentos: no primeiro, empregou-se a metade da quantidade de água do experimento anterior $(1 ; 1,25$ e $1,5 \mathrm{~mm}$ de água diária nas respectivas fases); no segundo, a lâmina de irrigação empregada foi a mesma da precipitação ocorrida no primeiro experimento (2; 2,5 e $3 \mathrm{~mm}$ de água diária por fase) e no terceiro, foi utilizado o dobro da quantidade de água usada no segundo tratamento (4; 5 e $6 \mathrm{~mm} \mathrm{~d}^{-1}$ por fase); no quarto tratamento utilizaram-se 1,$53 ; 2,5$ e $2,9 \mathrm{~mm} \mathrm{~d}^{-1}$ por fase, com base na depleção (Dep) do feijoeiro $(0,45)$ e na umidade do solo, utilizando-se sensores de extensão prolongada Gro-Point ${ }^{\mathrm{TM}}$, ajustados através do método gravimétrico, para o seu monitoramento.

Antecedendo a semeadura até o início da diferenciação dos tratamentos foram feitas sete irrigações em todo o experimento, totalizando $21 \mathrm{~mm}$ de água aplicada. Todas as parcelas foram uniformemente irrigadas para que o solo atingisse um índice de umidade que favorecesse a emergência e o estabelecimento da cultura. A diferenciação dos tratamentos, quanto à irrigação, teve início aos 22 dias após a semeadura (DAS) com a cultura na fase de emissão da terceira folha trifoliada. A partir desta data, a irrigação foi iniciada de modo diferenciado, conforme os tratamentos.

O sistema de irrigação adotado foi o manual, conforme Braga (1996) que relata que esse sistema fornece uma uniformidade de distribuição de água bem elevada. Nesse sistema, o emissor consiste de um tubo de PVC $(2,54 \mathrm{~cm})$ perfurado a cada $5 \mathrm{~cm}$, para a saída da água de irrigação, com $3 \mathrm{~m}$ de comprimento e apoio em cada extremidade, para manuseio dos operadores, os quais se deslocavam num movimento de vai-e-vem, ao longo do comprimento da parcela. Numa das extremidades do tubo foi conectada uma mangueira flexível, que serviu para abastecer o sistema.

A determinação da porcentagem de umidade do solo, que define o início da irrigação, foi obtida pela fórmula:

$$
\mathrm{U}=\{[(\mathrm{CC}-\mathrm{PM})(1-\mathrm{Dep})]+\mathrm{PM}\}
$$

donde:

CC - capacidade de campo, $\%$

PM - ponto de murcha, $\%$

Dep - limite máximo de perda de umidade da planta

A quantidade de água aplicada no tratamento foi definida pela seguinte fórmula: 


$$
\mathrm{L}=(\mathrm{CC}-\mathrm{U})(\operatorname{Prof} / 100)
$$

em que:

CC - capacidade de campo, $\%$

U - umidade do solo, $\%$

Prof - raio de atuação do sensor em conformidade com o comprimento das raízes

Utilizou-se a cultivar de feijão (Phaseolus vulgaris L.) Princesa (grupo carioca) com hábito de crescimento indeterminado tipo III, porte semi-prostado e, semanalmente, foram coletadas três plantas por tratamento nas quatro repetições, para a determinação da fitomassa (w), e analisadas conforme as diferentes fases fenológicas do feijoeiro. As amostras foram colocadas em estufa a $70^{\circ} \mathrm{C}$ até atingirem peso seco constante. Após o material ser retirado da estufa, foi pesado em balança com resolução de $0,01 \mathrm{~g}$, transformando-se o resultado para g/ amostra.

A área foliar (AF) foi analisada conforme as diferentes fases fenológicas do feijoeiro. Em cada amostra, folhas foram tomadas ao acaso e retirados discos de área conhecida. A relação entre o peso total das folhas secas e o peso dos discos secos forneceu a área foliar $\left(\mathrm{cm}^{2}\right)$.

$$
\mathrm{AF}=\frac{\text { Peso das folhas }}{\text { Peso dos discos }} \times \text { área dos discos }
$$

O índice de área foliar (IAF) de cada tratamento, nas fases fenológicas, foi obtido pela relação entre a área foliar (AF) e a área de solo amostrado $(\Delta \mathrm{S})$.

$$
\mathrm{IAF}=\frac{\mathrm{AF}}{\Delta \mathrm{S}}
$$

A relação entre o acúmulo da fitomassa total (W) e a unidade de área foliar (AF), durante a estação de crescimento, determina a taxa de assimilação líquida (TAL), em $\mathrm{g} \mathrm{cm}^{-2} \mathrm{~d}^{-1}$ (Fitter \& Hay, 1981), que foi determinada pela equação abaixo:

$$
\mathrm{TAL}=\frac{1}{\mathrm{AF}} \cdot \frac{\mathrm{dW}}{\mathrm{dt}}
$$

e a relação entre a área foliar (AF) e a fitomassa (W) define a razão de área foliar (RAF), em $\mathrm{cm}^{2} \mathrm{~d}^{-1}$, considerada medida da capacidade fotossintética de uma planta (Fitter \& Hay, 1981), dada pela seguinte equação:

$$
\mathrm{RAF}=\frac{\mathrm{AF}}{\mathrm{W}}
$$

\section{RESULTADOS E DISCUSSÃO}

O crescimento da planta como um todo, em termos de aumento de volume, de peso, de dimensões lineares e de unidades estruturais, é função do que a planta armazena e do que a planta produz em termos de material estrutural. Nas
Tabelas 1 e 2 encontra-se o resumo das análises de variâncias e as comparações das médias dos dados relativos às variáveis primárias do crescimento (fitomassa e área foliar).

Tabela 1. Resumo de análises de variância das variáveis primárias de crescimento do feijoeiro

\begin{tabular}{cccc} 
& & \multicolumn{2}{c}{ Quadrados Médios } \\
\cline { 3 - 4 } F.V. & G.L. & $\begin{array}{c}\text { Fitomassa } \\
\left(\mathrm{g} \mathrm{planta}^{-1}\right)\end{array}$ & $\begin{array}{c}\text { Área Foliar } \\
\left(\mathrm{cm}^{2}\right)\end{array}$ \\
\hline Blocos & 3 & 1,81 & $143.403,58$ \\
Tratamento & 3 & $857,12^{*}$ & $2.551 .658,25^{*}$ \\
Resíduo & 9 & 6,04 & $378.835,52$ \\
\hline
\end{tabular}

* Significativo ao nível de 5\% (Teste F)

Tabela 2. Médias* das variáveis primárias de crescimento do feijoeiro submetidos a diferentes tratamentos

\begin{tabular}{ccc} 
Tratamentos & $\begin{array}{c}\text { Fitomassa } \\
\left(\text { g planta }^{-1}\right)\end{array}$ & $\begin{array}{c}\text { Área Foliar } \\
\left(\mathrm{cm}^{2}\right)\end{array}$ \\
\hline T1 & $35,02 \mathrm{~d}$ & $3,730 \mathrm{~b}$ \\
T2 & $52,62 \mathrm{~b}$ & $5,058 \mathrm{ab}$ \\
T3 & $68,90 \mathrm{a}$ & $6,246 \mathrm{a}$ \\
T4 & $45,71 \mathrm{c}$ & $4,525 \mathrm{~b}$ \\
\hline CV $(\%)$ & 4,81 & 14,74 \\
\hline
\end{tabular}

"Médias seguidas da mesma letra nas colunas não diferem significativamente entre si, pelo Teste de Tukey a $5 \%$

A análise de variância, Tabela 1 revelou, efeitos significativos nos tratamentos. Na Tabela 2, verifica-se que na comparação das médias de tratamentos houve diferenças significativas. As diferenças de $\mathrm{W}$ entre tratamentos aumentaram proporcionalmente ao incremento das lâminas de água aplicadas. Os valores máximos da W foram 35,02; 52,62; 68,90 e 45,71 $\mathrm{g} \mathrm{planta}^{-1}$, obtidos aos 59 (DAS), nos respectivos tratamentos: $\mathrm{T} 1=80$; $\mathrm{T} 2=160, \mathrm{~T} 3=320$ e T4 $=140,2 \mathrm{~mm}$ de água, durante o ciclo do feijoeiro.

O acúmulo da fitomassa total (W), em função dos tratamentos e dos dias após a semeadura, é apresentado na Figura 1. Verifica-se que as curvas de crescimento apresentam característica sigmóide (Magalhães, 1979). Observa-se que, na $1^{\mathrm{a}}$ fase, o crescimento inicial da W é lento; nessa fase, que vai até os 37 DAS, a taxa de absorção de água e nutrientes é muito pequena para ativar os processos fisiológicos do crescimento, que exigem atividades metabólicas aceleradas. Na fase seguinte, a de floração, quando a planta alcança a idade de 37 - 45 DAS, o crescimento da W é mais rápido; nesta fase, estão formados o caule principal, os ramos e as folhas trifoliadas, bem como as tríades de gemas na axila de cada folha. Na $3^{\text {a }}$ fase, que vai de 45 - 67 DAS, observam-se dois períodos distintos: um onde o crescimento se torna mais intenso, atingindo o máximo aos 59 DAS, e outro em que a planta inicia o processo de senescência, que se reflete, inicialmente, na paralisação da produção de matéria orgânica; a partir daí, começam a prevalecer os fenômenos de translocação, em substituição ao de crescimento (Lopes et al., 1982 e 1983).

A redução progressiva de água, imposta aos tratamentos, provocou diminuição acentuada em $\mathrm{W}$ no final do experimento, o que, certamente, impôs uma redução no processo fotossintético. Estas observações estão em conformidade com trabalhos realizados por (Páez et al., 1995; Guimarães, 1996). 


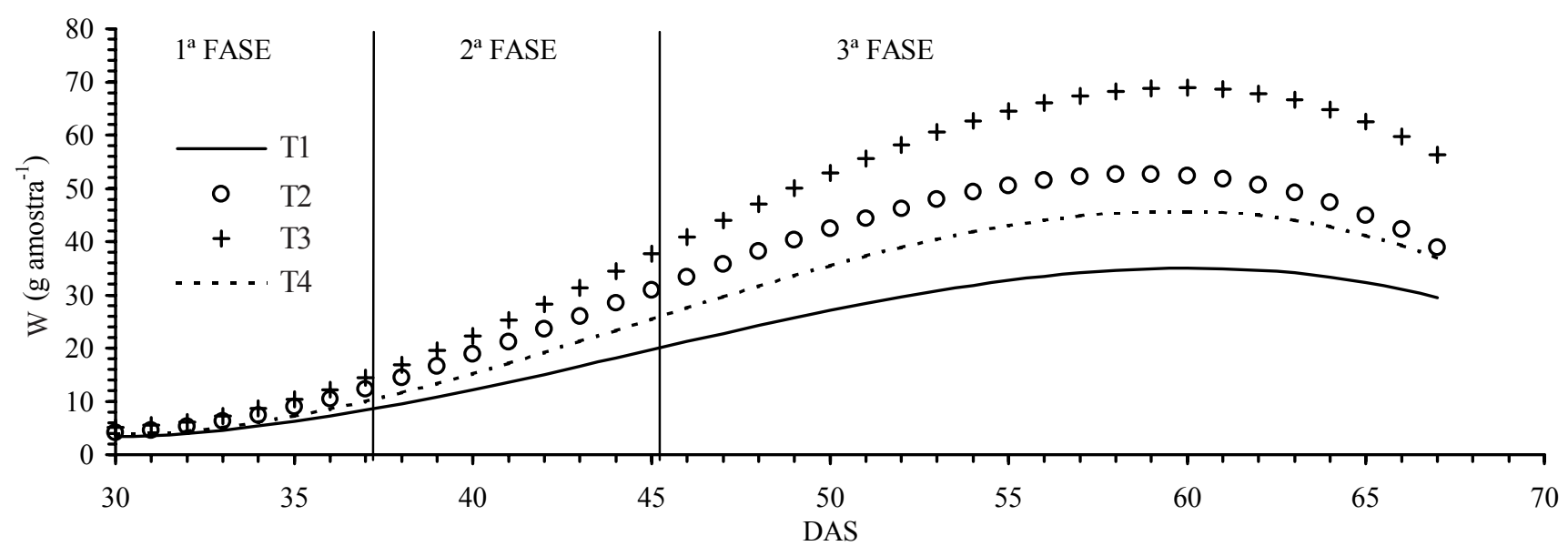

Figura 1. Fitomassa total (W) em relação aos dias após a semeadura (DAS), nas fases do feijoeiro, submetida aos diferentes tratamentos

As equações de ajuste para a fitomassa (W) seguiram o modelo polinomial do $3^{\circ}$ grau que, segundo os tratamentos, foram:

$$
\begin{array}{ll}
\text { T1 } & y=142,601-11,374 x+0,289 x^{2}-0,0028 x^{3} \\
\text { T2 } & y=241,180-19,482 x+0,500 x^{2}-0,004 x^{3} \\
\text { T3 } & y=316,097-25,053 x+0,630 x^{2}-0,005 x^{3} \\
\text { T4 } & y=210,447-16,680 x+0,421 x^{2}-0,003 x^{3}
\end{array}
$$

Nas Tabelas 1 e 2, verifica-se, através da análise de variância que o efeito de tratamentos foi significativo e, nas comparações das médias, observa-se diferenças significativas entre tratamentos.

Normalmente, a área foliar (AF) do feijoeiro aumenta com o incremento da umidade do solo, as folhas ficam mais túrgidas, o que determina maior expansão foliar, resultando, então, em maior eficiência fotossintética (Bascur et al., 1985b; Taiz \& Zeiger, 1991 e Fernández et al., 1996).

A tendência das curvas AF está representada na Figura 2, na qual se observa nitidamente o efeito gradativo da umidade do solo sobre a área foliar: AF aumentou proporcionalmente ao incremento da umidade do solo, imposta pelos tratamentos adotados no experimento. Observa-se, também, que a condição de proporcionalidade de aumento da AF se verificou em todas as fases do feijoeiro.
O crescimento de todas as curvas atingiu os valores máximos de $3.730,5.058,6.246$ e $4.525 \mathrm{~cm}^{2}$ na ordem dos tratamentos, aos $53 \mathrm{DAS}$, declinando gradativamente até o final do ciclo. O declínio de todas as curvas de AF, a partir dos $55 \mathrm{DAS}$, leva a crer que a senectude das folhas deve ter sobrepujado a emissão de novas folhas.

As equações de ajuste para a área foliar (AF) seguiram o modelo polinomial do $3^{\circ}$ grau que, segundo os tratamentos, foram:

$$
\begin{array}{ll}
\text { T1 } & \mathrm{y}=23802,91-1980,971 \mathrm{x}+52,760 \mathrm{x}^{2}-0,425 \mathrm{x}^{3}\left(\mathrm{R}^{2}=0,98\right) \\
\text { T2 } & \mathrm{y}=23427,714-2103,718 \mathrm{x}+59,558 \mathrm{x}^{2}-0,498 \mathrm{x}^{3}\left(\mathrm{R}^{2}=0,99\right) \\
\text { T3 } & \mathrm{y}=23085,272-2219,553 \mathrm{x}+65,793 \mathrm{x}^{2}-0,565 \mathrm{x}^{3}\left(\mathrm{R}^{2}=0,99\right) \\
\text { T4 } & \mathrm{y}=14694,852-1472,205 \mathrm{x}+44,818 \mathrm{x}^{2}-0,390 \mathrm{x}^{3}\left(\mathrm{R}^{2}=0,99\right)
\end{array}
$$

O comportamento dos índices de área foliar (IAF), determinado durante o ciclo da cultura, está apresentado na Figura 3, observando-se que o fator água influenciou nas variações do IAF. A diferença entre tratamentos relativa a essa variável tornou-se evidente a partir do $30^{\circ} \mathrm{DAS}$, correspondendo aos menores valores, enquanto os mais altos valores do IAF foram alcançados na $3^{\mathrm{a}}$ fase, aproximadamente no enchimento de vagens. Os valores máximos foram 2,98; 4,05; 5,00 e 3,62, obtidos aos 54, 53, 53 e 53 DAS, respectivamente e, na ordem dos tratamentos empregados, 80, 160,320 e 140,2 mm de água em todo o ciclo da cultura do feijão.

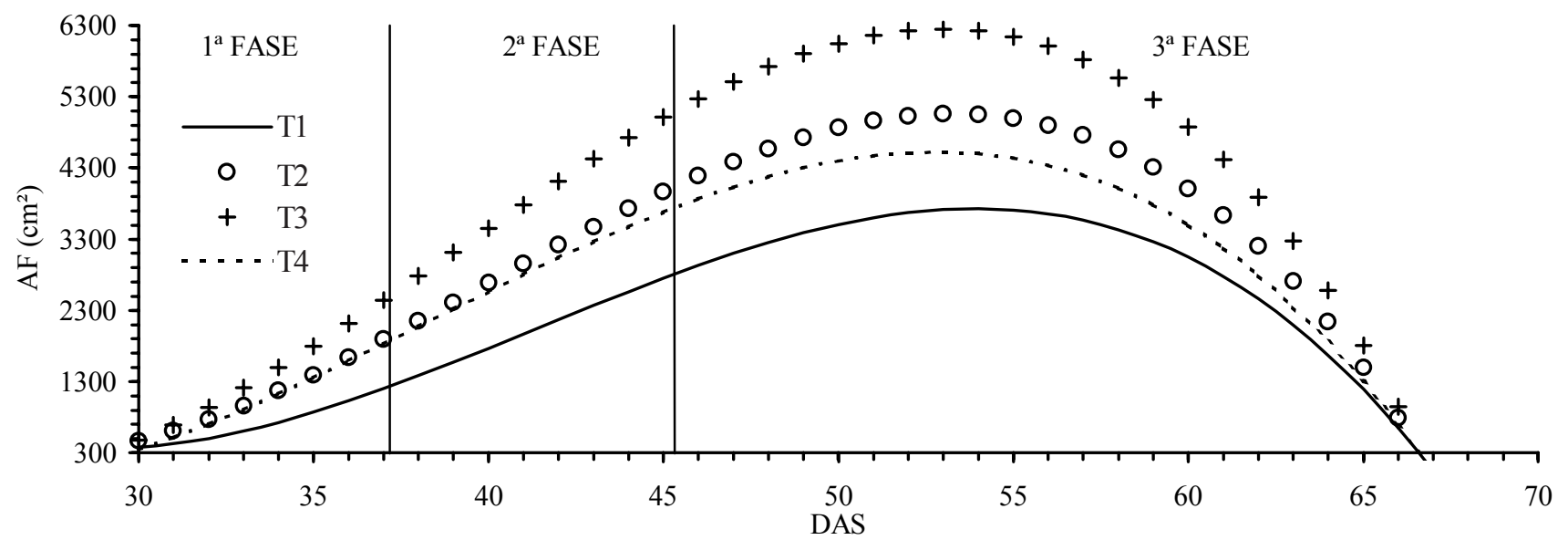

Figura 2. Área foliar (AF) em relação aos dias após a semeadura (DAS), nas fases do feijoeiro, submetida aos diferentes tratamentos 


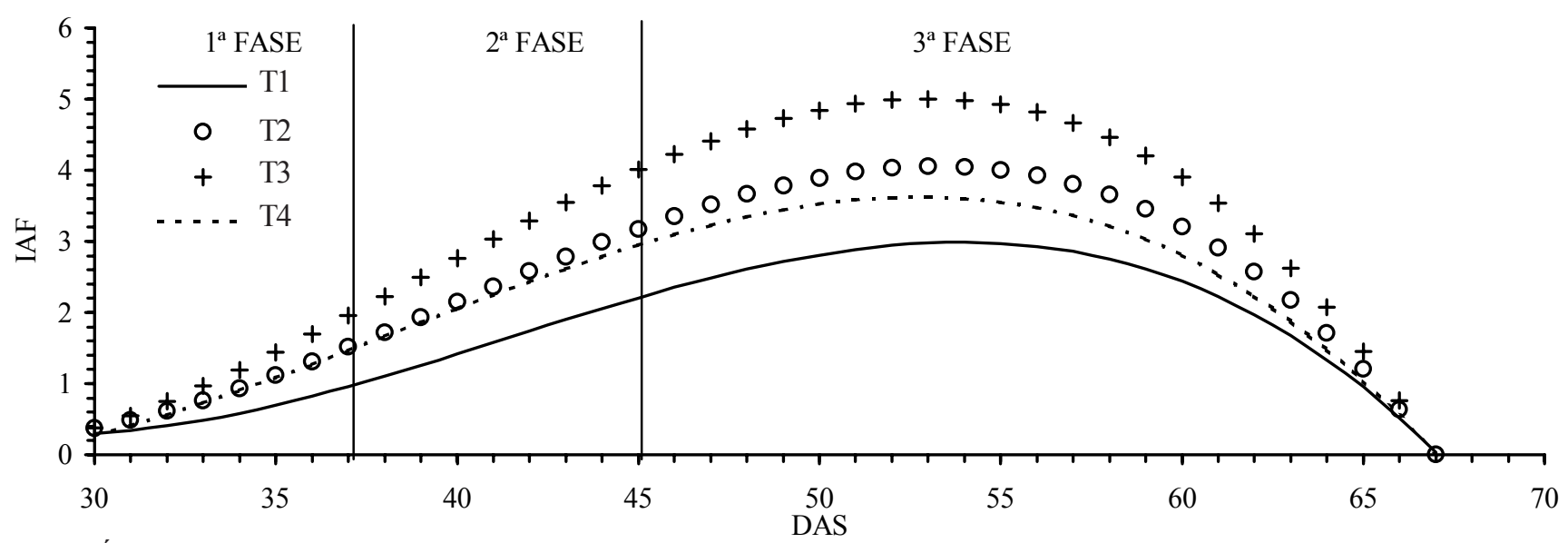

Figura 3. Índice de área foliar (IAF) em relação aos dias após a semeadura (DAS), nas fases do feijoeiro, submetido aos diferentes tratamentos

As equações de ajuste para o índice de área foliar (IAF) seguiram o modelo polinomial do $3^{\circ}$ grau que, segundo os tratamentos, foram:

$$
\begin{array}{lll}
\text { T1 } & y=18,986-1,582 x+0,042 x^{2}-0,001 x^{3} & \left(R^{2}=0,98\right) \\
\text { T2 } & y=18,746-1,684 x+0,048 x^{2}-0,001 x^{3} & \left(R^{2}=0,99\right) \\
\text { T3 } & y=18,493-1,778 x+0,053 x^{2}-0,001 x^{3} & \left(R^{2}=0,99\right) \\
\text { T4 } & y=11,757-1,178 x+0,036 x^{2}-0,001 x^{3} & \left(R^{2}=0,99\right)
\end{array}
$$

Em feijão, altos valores de IAF nem sempre estão correlacionados positivamente com o rendimento de grãos. Geralmente, ele é determinado a partir da relação entre área foliar total e área do solo disponível para a planta, que é definido pelo espaçamento estabelecido. À medida que a área foliar cresce, o IAF também cresce, até atingir um valor a partir do qual o auto-sombreamento passa a ser prejudicial, aumentando a superfície foliar, que é mantida sob iluminação precária, o que diminui bastante a sua eficiência fotossintética (Reis \& Muller, 1979). A ocorrência de IAF baixo, porém, limita a expressão do rendimento, visto que o mesmo representa o sistema acumulador da comunidade vegetal e pode ser considerado um importante fator da produtividade (Magalhães, 1979). Em muitos casos, é possível detectar-se o IAF ótimo, isto é, aquele que permite o máximo de fotossíntese e, conseqüentemente, taxa de crescimento da cultura elevada. Geralmente, o IAF ótimo ocorre nas primeiras fases do crescimento, quando o auto-sombreamento é mínimo. Muitas vezes, condições de auto-sombreamento que diminuem a eficiência fotossintética da cultura diminuem também a evapotranspiração a qual, na maioria dos casos, é mais limitante para a produtividade que a diminuição da fotossíntese líquida.

A taxa de assimilação líquida (TAL), apresentada na Figura 4, atingiu valores máximos de 0,$0011 ; 0,0012 ; 0,0010$ e $0,009 \mathrm{~g} \mathrm{~cm}^{-2} \mathrm{~d}^{-1}$, obtidos aos 33 DAS, na ordem dos tratamentos $80,160,320$ e $140,2 \mathrm{~mm}$ de água, durante o ciclo da cultura. Verifica-se que na $1^{\text {a }}$ fase os tratamentos com menores disponibilidades hídricas suplantaram os que receberam quantidade de água maior; no entanto, nas fases seguintes prevaleceram os tratamentos com maior aplicação de água. Esses resultados estão de acordo com as observações feitas por Costa et al. (1989) de que a TAL varia mais com a idade da planta que com os fatores ambientais. Observações de Resende et al. (1981) chamam a atenção para o fato de que o feijoeiro, ao adquirir resistência à deficiência hídrica, mantém o potencial hídrico foliar e a resistência estomatal mais baixos e, desta maneira, a taxa assimilatória líquida não é afetada. Este efeito é considerado resultante da capacidade do feijoeiro em se adaptar a diferentes condições ambientais, dentro de certos limites.

Na Figura 5, verifica-se que os valores máximos da razão da área foliar (RAF) foram obtidos na $1^{\text {a }}$ fase, em todos os tratamentos entre 34 e 35 DAS. Esses dados permitem verificar, também, que RAF declina à medida que a planta cresce, o que é perfeitamente

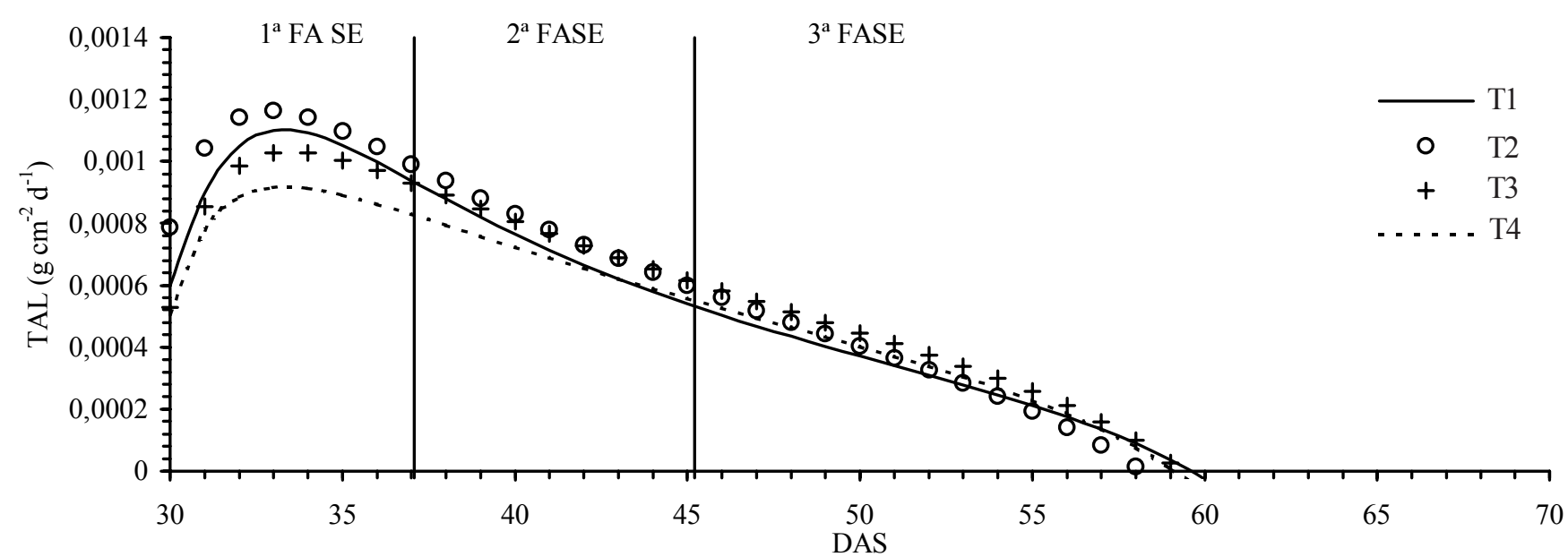

Figura 4. Taxa de assimilação líquida (TAL) em relação aos dias após a semeadura (DAS), nas fases do feijoeiro, submetida aos diferentes tratamentos 


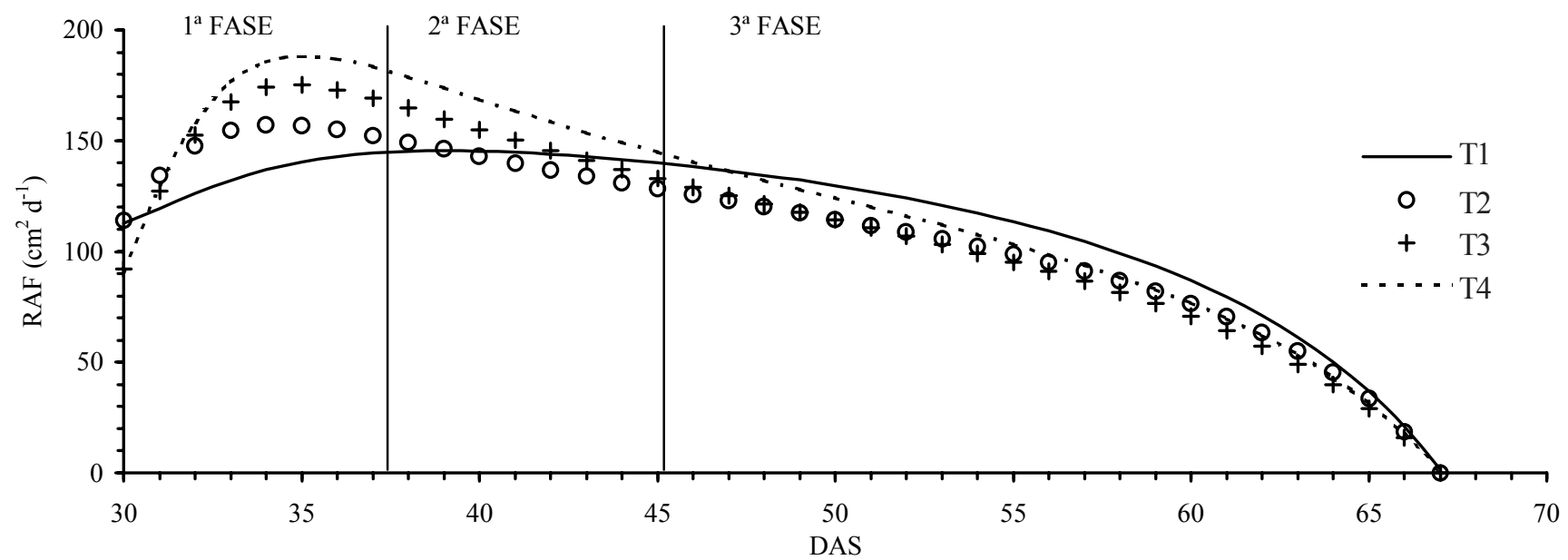

Figura 5. Razão de área foliar (RAF) em relação aos dias após a semeadura (DAS), nas fases do feijoeiro, submetida aos diferentes tratamentos

compreensível pois, com o crescimento, aumenta a interferência de folhas superiores sobre folhas inferiores (auto-sombreamento); a tendência, então, é a área foliar útil diminuir a partir de certa fase. Este declínio, observado nas curvas de RAF com o crescimento da planta, indica também o aumento da queda de folhas e da redução da quantidade de assimilados para a produção de novas folhas (Scott \& Batchelor, 1979 e Costa et al., 1989).

Os valores máximos da RAF, 145,44; 136,04; 175,20 e $188,00 \mathrm{~cm}^{2} \mathrm{~d}^{-1}$ foram obtidos, respectivamente, para os tratamentos: $\mathrm{T} 1=80, \mathrm{~T} 2=160, \mathrm{~T} 3=320$ e T4 $=140,2 \mathrm{~mm}$ de água em todo o ciclo da cultura no experimento. Observa-se que, no T4, o valor máximo foi superior aos valores dos $\mathrm{T} 2$ e T3, que receberam maior suprimento de água.

No T4, o intervalo de rega era menor, apesar de receber quantidade de água inferior, o que resultou, provavelmente, na redução da resistência estomática, possibilitando maior taxa de área foliar útil para a fotossíntese (Almeida et al., 1988).

\section{CONCLUSÕES}

1. Os diferentes tratamentos empregados determinaram variações sobre o crescimento do feijoeiro. Fica evidente a influência dos diferentes níveis de umidade no solo sobre os processos fisiológicos.

2. A competição por água, imposta pelos diferentes tratamentos, condicionou as plantas a variações na produção de fitomassa nas taxas da área foliar, índice de área foliar, assimilação líquida e na razão da área foliar.

3. Ocorreu comportamento diferenciado nas variáveis de crescimento do feijoeiro, sob diferentes lâminas de irrigação. A redução da umidade no solo influenciou os processos fisiológicos, resultando na diminuição do crescimento foliar, o qual está associado positivamente à inibição da atividade fotossintética, o que limitará o rendimento da cultura.

\section{LITERATURA CITADA}

Almeida, A.A.F. de; Lopes, N.F.; Oliva, M.A.; Barros, R.S. Desenvolvimento e partição de assimilados em Phaseolus vulgaris submetido a três doses de nitrogênio e a três níveis de luz. Pesquisa Agropecuária Brasileira, Brasília, v.23, n.8, p.837-847, 1988 .
Bascur, G.; Oliva, M.A.; Laing, D. Termometria infrarroja en seleccion de genotipos de frijol (Phaseolus vulgaris L.) resistentes a la sequia. I. Bases fisiologicas. Turrialba, São José, v.35, p.43-47, 1985a.

Bascur, G.; Oliva, M.A.; Laing, D. Termometria infrarroja en seleccion de genotipos de frijol (Phaseolus vulgaris L.) resistentes a sequia. II. Crecimiento y productividad. Turrialba, São José, v.35, p.49-53, 1985b.

Braga, M.B. Estudo e análise da profundidade efetiva do sistema radicular do feijoeiro (Phaseolus vulgaris L.) sob quatro freqüências de irrigação. Viçosa: UFV, 1996. 67p. Dissertação Mestrado

Costa, R.C.L.; Lopes, N.F.; Oliva, M.A.; Barros, R.S. Crescimento e conversão de energia solar em feijão submetido a três doses de nitrogênio e dois regimes hídricos. Pesquisa Agropecuária Brasileira, Brasília, v.24, n.12, p.1439-1450, 1989.

Fancelli, A.L; Dourado Neto, D. Feijão irrigado. 2.ed, Piracicaba: ESALQ/USP, 1991.266p.

Fernández, C.J.; Mcinnes, K.J.; Cothren, J.T. Water status and leaf area production in water - and nitrogen-stressed cotton. Crop Science, Madison, v.36, p.1224-1233, 1996.

Fitter, A.H.; Hay, R.K.M. Environmental physiology of plants. Academic Press, New York: 1981. p.7-13, 50-55.

Guimarães, C.M. Relações hídricas. In: Araújo, R.S.; Rava, C.A.; Stone, L.F. Cultura do feijoeiro comum no Brasil. Piracicaba, SP: POTAFOS. 1996. 786p.

Guimarães, C.M.; Steinmetz, S.; Portes e Castro, T. de A. Uso de microlisímetros na determinação da evapotranspiração do feijoeiro da seca. In: Reunião Nacional de Pesquisa de Feijão 1, 1982, Goiânia. Anais. Goiânia, EMBRAPA-CNPAF, 1982. p.133-137.

Lopes, N.F.; Oliva, M.A.; Freitas, J.G.; Melges, E.;. Beltrão, N.E. de M. Análise de crescimento e conversão da energia solar em feijoeiro (Phaseolus vulgaris L.) submetido a três níveis de densidade do fluxo radiante. Ceres, Viçosa, v.29, p.586-606, 1982.

Lopes, N.F.; Oliva, M.A.; Melges, E. ; Furtado, M.H.; Freitas, J.G. Crescimento, morfologia, partição de assimilados e produção de matéria seca do feijão (Phaseolus vulgaris L.) submetido a três níveis de densidade do fluxo radiante. Ceres, Viçosa, v.30, p.451-462, 1983. 
Magalhães, A.C.N. Análise quantitativa do crescimento. In: Ferri, M.G. (Coord.). Fisiologia vegetal, v.1. São Paulo: EPU/ Ed. USP. 1979 p.331-350.

Magalhães, A.C.N. Fotossíntese. In:. Ferri, M.G. (Coord.). Fisiologia vegetal, v.1. São Paulo: EPU/Ed. USP. 1979. p.117-163.

Mañas, F.M.S.O.; Valero, J.A.J. Agronomia del riego. Madrid: Mundi-Prensa, 1993. 732p.

Páez, A.; Gonzáles, M.E.; Yrausquín, O.X. Water stress and clipping management effects on guinea grass: I. Growth and biomass allocation. Agronomy Journal, Madison, v.87, p.698-706, 1995.

Reis, G.G. dos; Müller, M.W. Análise de crescimento de plantas; mensuração do crescimento. Belém: Faculdade de Ciências Agrárias do Pará, 1979. 39p. Informe Didático 1
Resende, M.; Henderson, D.W.; Fereres, E. Freqüência de irrigação, desenvolvimento e produção do feijão Kidney. Pesquisa Agropecuária Brasileira, Brasília, v.16, n.3, p.363-370, 1981.

Scott, H.D. ; Batchelor, J.T. Dry weight and leaf area production rates of irrigated determinate soybeans. Agronomy Journal, Madison, v.71, p.776-782, 1979.

Stone, L.F.; Moreira, J.A.A.; Silva, S.C. da. Efeitos da tensão da água do solo sobre a produtividade e o crescimento do feijoeiro. I. Produtividade. Pesquisa Agropecuária Brasileira, Brasilia v.23, n.2, p.161-167, 1988.

Taiz, L.; Zeiger. Plant physiology. Redwood City: The Benjamim/ Cummings Publishing Company, Inc., 1991. 